\title{
RESENHA DE CONTRA OS FILHOS DE LINA MERUANE. SÃO PAULO: TODAVIA, 2018
}

Luisa Destri

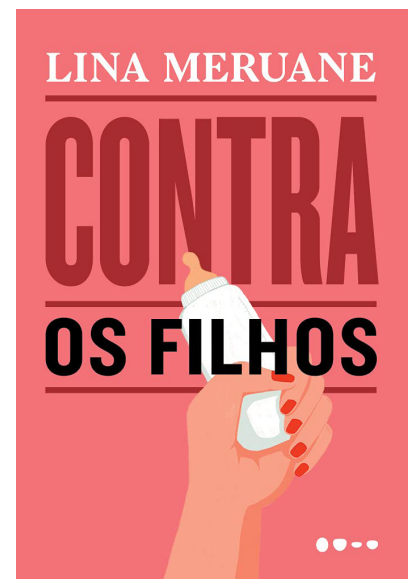

Para adjetivar sucintamente Contra os filhos - uma diatribe, de Lina Meruane, talvez fosse possível convocar um velho clichê da academia: trata-se de um livro irregular. O termo descreveria, com precisão e em primeiro lugar, os seus movimentos, em que sete capítulos se sucedem acelerando e reduzindo o ritmo, aumentando e diminuindo a densidade, intensificando ou abrandando a provocação. Poderia se aplicar também à diversidade dos registros, já que a tendência objetiva e persuasiva às vezes é interrompida por alguma petulância. E seria justo, sobretudo, em termos da força dos argumentos, que ora 
parece advir de pesquisas, ora da mera amplificação de impressões pessoais. Nada disso importaria, porém, se não fosse enorme a sua capacidade de colocar questões essenciais - provavelmente na mesma medida em que promove indignação.

O ponto de partida é a contradição identificada no seio daquilo que a autora nomeia a "máquina reprodutiva": de um lado, a necessidade da procriação para assegurar a continuidade da espécie; de outro, o "excesso consumista e contaminador que está acabando com o planeta". Dessa contradição, Meruane deriva uma série de paradoxos, como a "propaganda procriadora frenética e contraditória" realizada por um Estado incapaz de distribuir recursos de forma igualitária e, assim, erradicar a pobreza. Os resultados desses processos vêm todos desembocar no corpo feminino, ignorando escolhas: as mulheres que optam por não ter filhos são assediadas a todo momento pela "cantata da procriação", já as mães assumem um fardo que o processo histórico foi tornando cada vez mais pesado.

Para demonstrar a forma específica como hoje a maternidade - "uma palavra de ordem à prova de revoluções, um dogma contrarrevolucionário" - sustém o patriarcado e atende a interesses capitalistas, duas estratégias principais 
são empregadas. Primeiro, a síntese histórica das condições para o exercício da maternidade, que tem na literatura e no ofício de mulheres escritoras um eixo central. Segundo, a discussão sobre o que Meruane entende como o ideal contemporâneo de maternidade, caracterizado por um excesso de obrigações e pela necessidade de atender aos filhos como se de clientes se tratasse.

Inicialmente se realiza um recuo até figuras emblemáticas que, a exemplo de Sor Juana Inés de la Cruz, empreenderam buscas mais ou menos solitárias pela igualdade intelectual. Um exemplo fundamental é o da ativista francesa Olympe de Gouges (pseudônimo de Marie Gouze), guilhotinada após mostrar, com sua Declaração dos direitos da mulher e da cidadã (1791), que já na Revolução Francesa era falsa a ideia do "homem" como um sujeito universal, representante de toda a humanidade. Avançando um século, Meruane relembra como a Primeira Guerra levou as mulheres a se profissionalizarem fora de casa, convocando-as de volta ao fim do conflito, que além disso as colocou sob o imperativo da procriação. Esse é contexto em que surge Virgina Woolf, cujas condições materiais Ihe permitem conquistar um teto sob o qual empreende uma luta psíquica, como afirma a ensaísta chilena: "Perturba a escritora essa imagem da 
esposa-mãe idealizada que aparece em todos os âmbitos da vida social, assim como dentro da casa e de sua cabeça, enquanto ela escreve".

É nas incursões pela literatura que o ensaio de Meruane se torna mais saboroso. A partir de Casa de bonecas (1879) e da polêmica decisão da protagonista de Ibsen, a autora mostra como a celebração feminista da partida de Nora é parcial: "O que é das mulheres quando elas vão embora? Elas podem conseguir o que querem, podem triunfar nas suas aspirações?". A resposta a essa pergunta passa pela centralidade das condições materiais, "que as feministas educadas e acomodadas não levaram em consideração precisamente porque estavam mais ou menos resolvidas para elas". Ela convoca então a escritora austríaca Elfriede Jelinek, Nobel de Literatura em 2004, e sua peça O que aconteceu depois que Nora deixou seu marido ou Os pilares da sociedade para mostrar o que acontece a mulheres que aspiram à emancipação sem ter meios de ampará-la. Esta Nora de 1979 a remete para as operárias de Pagu, cujo Parque industrial (1933) revela a distância que separa as mulheres em classes.

Caracterizada a centralidade da questão material, Meruane passa a debater o que chama de "dilema 
materno-escritural", já que as escritoras têm um desafio adicional quando o assunto é a maternidade. Enquanto as "criadoras-sem-filhos" acumulam o ofício não remunerado da escrita com o trabalho assalariado, as "criadoras-comfilhos" têm tripla jornada. "Se para a criadora-sem-filhos ter dois trabalhos interfere na sua obra, para a outra, comfilhos, as horas do dia se mostram insuficientes porque, ao horário assalariado, é preciso acrescentar a implacável rotina materna e então: de onde tirar o espaço temporal e mental para o ofício criativo?". (Sabemos que basta trocar "criadora-com-filhos" para "pesquisadora-com-filhos" para que o dilema se aplique a muitas das leitoras, já que boa parte do trabalho acadêmico, quando não a sua totalidade, não é remunerado.) Depois de elaborar uma lista bastante útil de escritoras que não tiveram filhos - "uma avassaladora maioria", que inclui de Santa Teresa de Ávila a Anaïs Nin, de Jane Austen a Alejandra Pizarnik, de Gertrude Stein a Victoria Ocampo -, o ensaio então discute como ao longo da história as mulheres conseguiram (ou não) conciliar maternidade e escrita. A partir da experiência sobretudo autoras de língua espanhola, extrai cinco teses:

1) “Escrever e criar é uma verdadeira façanha para uma pessoa que, além disso, precisa de um salário." 
2) Mulheres que escreveram e brilharam não tiveram filhos ou os abandonaram.

3) Quem conseguiu escrever tendo filhos tinha uma fortuna.

4) "As que tiveram filhos e não contaram com meios, suspenderam o ofício por um prolongado e doloroso período e escreveram muito depois, ou pouco, ou simplesmente renunciaram."

5) "As que geraram e criaram e escreveram e trabalharam ao mesmo tempo são autênticas exceções".

Até aqui, não há qualquer irregularidade no ensaio de Meruane, que, embora não se pretenda uma pesquisa formal sobre o tema, é eficaz em mostrar, na sua brevidade, as principais fontes e os principais aspectos do debate. Quando, a partir do quinto capítulo, "Tipos de mãe", tenta compreender as questões atuais da maternidade, algo estranho e delicado acontece. Poderia ser o caso de invocar o conceito de lugar de fala, embora a identidade da mulher sem filhos dê conta de quase toda a perspectiva assumida no livro. Mas há também certa relação com os movimentos históricos do feminismo, que em um primeiro momento, o de Simone de Beauvoir e Betty Friedan, viu na maternidade apenas um instrumento do patriarcado 
para oprimir as mulheres, mas que a partir da década de 1970 passou a nela reconhecer uma importante experiência feminina. Reduzindo o debate à oposição entre "feministas igualitárias" e "feministas da essência", Meruane desqualifica uma terceira etapa desse debate, aquela que desde a década de 1980 vem se empenhando em unir as duas tendências, como mostra Elaine Tuttle Hansen em Mother without child (1997), livro dedicado à representação ficcional da maternidade. Com esse recurso, a ensaísta qualifica-se a si mesma como "antiquada", opondo-se assim às mães atuais, que, na sua leitura, acreditam-se emancipadas mas são, em suas escolhas supostamente compulsórias, sujeitadas pelo patriarcado de forma cada vez mais intensa. Ela parece querer alertar: "as essencialistas foram enfeitiçadas pelo anjo-materno agora vestido de verde", afirma, em referência a um padrão contemporâneo de maternidade que, atento a questões ecológicas, inclui o uso de fraldas de pano, a prolongação da lactação, o retorno ao parto sem anestesia, o cuidado próximo e abarcando questões de saúde e aprendizagem - todo um excesso de responsabilidades, enfim, diante das quais as famílias tentam oferecer às crianças aquilo que a sociedade deveria ser capaz de assegurar. 
É fascinante o passo seguinte da argumentação, mas antes de identificá-lo vale apontar uma relevante falha. A autora enaltece a "fórmula láctea da liberação" a fim de criticar a amamentação prolongada, como se a ciência já não tivesse se encarregado de mostrar que, embora representem uma excelente alternativa, a mamadeira e o leite em pó são, efetivamente, uma alternativa. A defesa do aleitamento materno surge nas páginas do livro como coisa de "proselitistas do leite", cujo efeito final é excluir "o pai incompetente e mal treinado que se distrai feliz em outras atividades". A autora se revela, para dizer o mínimo, desatualizada e mal informada, como aliás já mostrou Ilana Feldman (2019) em excelente resenha. Além disso, se buscasse um ponto de vista mais interno à realidade dessas mães, Meruane talvez pudesse vislumbrar que é justamente nesse "nicho" que as mulheres mais lutam pela modificação do papel masculino na criação ou, melhor, talvez pudesse ver como o aleitamento materno fornece a ocasião para que muitas mulheres se unam em redes de suporte e solidariedade, com o intuito de superar o que é justamente apontado por Meruane como o cerne do problema: "a procriação como questão cada vez mais privada".

O trabalho argumentativo poderia, nesse sentido, beneficiar-se de alguma dialética. É indiscutível, porém, 
a afirmação de que a criação dos filhos hoje se tornou uma espécie projeto pessoal. Neste aspecto está sua contribuição mais impressionante - a passagem que a sintetiza vale a citação:

Essa maternidade total não só coloca a mãe num lugar da escada, mas situa os filhos vários degraus acima na hierárquica escalada da sobrevivência e do progresso da qual a mãe parece a única responsável. Porque a obrigação atual da mãe é oferecer a seus filhos vantagens comparativas num mundo cada vez mais competitivo, e essas vantagens começam a ser trabalhadas na gravidez, passam pelo parto e se alongam na lactação e na afeição e continuam no constante estímulo intelectual e nas tarefas feitas em conjunto, até o inalcançável horizonte dos etcs.

Para avançar um pouco mais: em tempos da subjetividade empreendedora governada pelo neoliberalismo (para usar os termos de Dardot e Laval), os filhos servem a uma espécie de "valoração da competição desleal". Tudo se passa como se as mães, com poucos recursos, devessem ser capazes de oferecer o máximo aos seus filhos, produzindo resultados na área da saúde, da educação, da nutrição. 0 fato de estarem sobrecarregadas é, para Meruane, político: "suspeito que mantê-las ocupadas é, precisamente, o que as impede de elaborar um pensamento crítico de sua situação 
e fazer alguma coisa. Porque não há outra alternativa além de colocar suas ásperas mãos na questão", completa, em referindo-se à possibilidade de alguma mudança.

A chamada para a ação talvez conseguisse ganhar força caso o livro se encerrasse por aí. Infelizmente, porém, há um capítulo final, intitulado "O império dos filhos", empenhado em demonstrar como a "crescente pressão em torno da criação" está supostamente produzindo adolescentes abusivos, cujo comportamento demanda "inofensiva e até necessária punição disciplinar". Novamente a autora se revela desatualizada, ignorando os debates sobre a formação de vínculos na criação dos filhos ao sugerir que o empenho cuidadoso dos pais é a causa de futuros atos violentos, que a seus olhos parecem bastante disseminados entre crianças e adolescentes. Nesse passo, em vez de assumir o papel que poderia lhe caber na denúncia da sobrecarga do trabalho familiar, em um esforço construtivo que efetivamente convidasse à ação, o livro resvala para um debate moralista, em uma defesa da "palmada" que nada tem a ver com a sofisticação de outras passagens.

Talvez o tropeço se deva ao contexto de origem do livro. Contra os filhos foi publicado inicialmente pela independente Tumbona Ediciones, do México, como parte da coleção 
Versus, que conta com títulos como Contra el Amor, Contra el Copyright, Contra el Trabajo, Contra la Belleza, Contra la Alegría de Vivir, entre outros. Nesse contexto, o humor provocativo e a caracterização dos filhos como "anões executores de um imperativo de serviço doméstico que continua mais vivo e ativo do que nunca" podem ter como função tornar mais palatáveis os debates feministas e a crítica ao neoliberalismo, o que explicaria a redução de sua força. Mesmo que se trate de uma estratégia, é contudo uma pena. Justamente agora, quando as medidas de isolamento social para conter a pandemia intensificaram o processo de transferência de responsabilidade sobre as crianças para o âmbito totalmente doméstico, as reflexões seriam mais que necessárias. "Quatro braços e dois corpos e 24 horas no dia já não bastam, porque no quartel doméstico se duplicaram as ocupações e as responsabilidades", afirma Meruane, antes mesmo que o ensino remoto e outras contemporaneidades se tornassem realidade. Como um livro que se baseia no argumento de que "a cada êxito feminista se seguiu um retrocesso, a cada golpe feminino um contragolpe social destinado a domar os impulsos centrífugos da liberação", sua leitura seria perfeita para o intervalo entre um golpe, um contragolpe e algumas trocas de fraldas. 


\section{REFERÊNCIAS}

DARDOT, Pierre; LAVAL, Christian. Néolibéralisme et subjectivation capitaliste. Cités, n. 41, p. 35-50, 1/2010. Disponível em www.cairn.info/ revue-cites-2010-1-page-35.htm. Acesso em 06 mar. 2021.

FELDMAN, Ilana. A tirania dos filhos - sobre "Contra os filhos", de Lina Meruane. Quatro cinco um - revista de livros. Ano II, número 16, out. 2019, p. 43-44.

MERUANE, Lina. Contra os filhos - uma diatribe. São Paulo: Todavia, 2018. TUTTLE, Elaine. Mother Without Child: Contemporary Fiction and the Crisis of Motherhood, Berkeley: University of California Press, 1997.

\section{Luisa Destri}

Doutora em Literatura Brasileira pela Universidade de São Paulo (2016). Há mais de dez anos trabalha entre as duas áreas de formação Jornalismo e Letras -, desempenhando atividades que conjugam a formação literária e a prática jornalística, como condução de pesquisas, ensino de produção textual e produção de conteúdo.

Contribui como redatora para a Enciclopédia de Arte e Cultura Brasileira do Itaú Cultural, entre outras colaborações.

E-mail: luisadestri@gmail.com

Lattes: http://lattes.cnpq.br/8362436882325864

ORCID iD: http://www.orcid.org/0000-0003-2360-1872 